\title{
IDENTIDADE E DIFERENÇA SOB A PERSPECTIVA DOS CORPOS TRANS: POSSIBILIDADES PARA UMA SOCIEDADE PLURAL
}

\author{
Noli Bernardo Hahn ${ }^{1}$ \\ Lucimary Leiria Fraga ${ }^{2}$
}

\begin{abstract}
Resumo:
O eixo central deste ensaio se delimita ao contexto identitário, abordando características acerca de seu processo de construção. Adentra na identidade Trans, a qual diverge do ideal binário (macho/fêmea), historicamente imposto como padrão na sociedade. Analisam-se perspectivas distintas de diferença e de como esta categoria se apresenta nas vivências das identidades ora referidas. A metodologia mescla análise e interpretação. Pela análise, esclarecem-se conceitos, especialmente o de identidade e o de diferença. Através da hermenêutica, interpretam-se estes conceitos para uma compreensão em que se abrem fissuras para a ótica de alteridade e a um olhar que transcenda a perspectiva binária.
\end{abstract}

Palavras-chave: Identidade. Identidade Trans. Diferença. Alteridade. Reconhecimento

\section{IDENTITY AND DIFFERENCE UNDER THE PERSPECTIVE OF TRANS BODIES: POSSIBILITIES FOR A PLURAL SOCIETY}

\begin{abstract}
:
The central axis of this essay is limited to the identity context, addressing characteristics about its construction process. It enters into the Trans identity, which diverges from the binary ideal (male / female) historically imposed as a standard in society. Different perspectives of difference and how this category is presented in the experiences of the identities mentioned above are analyzed. The methodology mixes analysis and interpretation. The analysis clarifies concepts, especially identity and difference. Through hermeneutics, these concepts are interpreted for an understanding in which cracks open the optics of alterity and to a look that transcends the binary perspective.
\end{abstract}

\footnotetext{
1 Pós-doutor pela Faculdades EST, São Leopoldo, RS. Graduado em Filosofia pela Faculdade de Filosofia, Ciências e Letras Dom Bosco, Santa Rosa/RS. Bacharel em Teologia pelo Instituto Missioneiro de Teologia (IMT), Santo Ângelo/RS. Mestre em Teologia com concentração em estudos bíblicos pela Faculdade de Teologia Nossa Senhora da Assunção, São Paulo/SP, e Doutor em Ciências da Religião, área de concentração ciências sociais e religião pela Universidade Metodista de São Paulo - UMESP. Possui formação em DIREITO. É professor tempo integral da Universidade Regional Integrada do Alto Uruguai e das Missões. Integra o corpo docente como professor permanente do PPG Mestrado e Doutorado em Direito da URI, Campus de Santo Ângelo. Pesquisa temas inter-relacionando Direito, Cultura e Religião. E-mail: nolihahn@san.uri.br.

Mestranda em Direito pelo PPG Stricto Sensu da Universidade Regional Integrada do Alto Uruguai e das Missões (URI), Campus de Santo Ângelo. Bolsista CAPES/PROSUC. Bacharela em Direito pela Universidade Regional Integrada do Alto Uruguai e das Missões (URI) Campus de Santo Ângelo. Instrutora de trânsito (URI). "Pesquisadora do Grupo de Pesquisa Direito, Cultura e Religião: conexões e interfaces", o qual se vincula à linha de pesquisa Direito e Multiculturalismo, do Programa Stricto Sensu Mestrado e Doutorado em Direito da Universidade Regional Integrada do Alto Uruguai e das Missões, URI Campus de Santo Ângelo-RS. Membro do Grupo de Pesquisa Novos Direitos em Sociedades Complexas, vinculado ao Programa Stricto Sensu Mestrado e Doutorado em Direito da Universidade Regional Integrada do Alto Uruguai e das Missões, URI Campus de Santo Ângelo-RS (CNPQ). Pesquisa temas relacionados a mulheres Trans, identidade, cultura e diferença. E-mail: lucimary23@ hotmail.com.
} 
Keywords: Identity. Trans identity. Difference. Alterity. Recognition

\section{INTRODUÇÃO}

Este artigo centra-se no tema das múltiplas formas identitárias que transitam na sociedade, as quais, nas trocas sociais ao longo do espaço-tempo, se constroem de forma individual, mas, igualmente, coletiva. Pelo pressuposto da construção histórica, jamais as identidades se moldaram de forma estanque. Neste sentido, o questionamento central formulado nesta reflexão tem a ver com a ideia de que a sociedade caminha para o respeito aos corpos e identidades Trans, seja pelo viés jurídico, ou meramente social, partindo do pressuposto de que a "diferença" pode (e deve) ser vista como positiva, na medida em que uma identidade não busque dominar outra, mas, sim, para que todas as manifestações identitárias possam conviver com respeito e reconhecimento de alteridade. A pergunta, no entanto, que se elabora é esta: A sociedade possui como horizonte o reconhecimento da alteridade, tanto no nível jurídico, como no nível social?

Para responder esta questão, num primeiro momento, faz-se breves considerações sobre identidade e sua constituição. Nessas considerações é fundamental a percepção da construção de identidades. Enquanto construção, não se entende uma identidade dada, fixa, no sentido de esta se constituir de uma vez por todas e sendo assim toda a vida.

Em um segundo momento, busca-se compreender a categoria diferença. Esta categoria é central para se compreender os distintos temas que se entrelaçam entre si. Violência é um desses temas. A relação com o diferente, na história humana, sempre foi marcada com violência. O diferente sempre foi visto e não ouvido. Enxergava-se o diferente para ser excluído ou eliminado. Ele não poderia ser integrado como diferente. Enquanto diferente, não havia e não há, ainda hoje, em grande medida, espaço para ele. Outro tema é exclusão. O diferente necessariamente terá de ser excluído quando sua presença incomoda e ou atrapalha. Um terceiro tema é alteridade. Alteridade supõe e pressupõe ouvir o outro enquanto outro. Nesta segunda parte do artigo, reflete-se, portanto as distintas inter-relações para se compreender a categoria de compreensão diferença.

Como terceiro passo da reflexão, adentra-se na seara dos corpos Trans, os quais, por meio de suas identidades móveis, apresentam-se socialmente carregados desta "diferença" e, 
na medida em que transitam nos espaços sociais, buscam transcender o ideal binário de gênero e identidades, a fim de viverem com dignidade e liberdade. Nesta terceira parte do artigo, a identidade Trans é o tema central, buscando-se compreender o quanto a diferença deve ser ouvida, enquanto alteridade, para não se cometer violências contra tais identidades.

Como objetivo geral, reflete-se acerca da identidade, procurando compreender como se constituem as identidades, propiciando, assim, a possibilidade de se construir socialmente e juridicamente uma consciência de alteridade em relação à diferença, especialmente no que diz respeito aos corpos Trans.

No intuito de buscar aparatos para uma melhor compreensão da questão central acima proposta, utiliza-se como metodologia a abordagem analítica, em função de esclarecer conceitos, e de uma abordagem hermenêutica, com o intuito de possibilitar a compreensão da perspectiva de alteridade, transcendendo, assim, um entendimento binário e muito restrito de diferença. Essa hermenêutica abre rastros para outro entendimento aos corpos Trans, pois estes não se enquadram nos modelos hierárquicos e fixos de identidade.

\section{IDENTIDADE E SUA CONSTITUIÇÃO: BREVES CONSIDERAÇÕES}

Setton, ao analisar a teoria do habitus de Pierre Bourdieu, parte do seguinte questionamento: "Como compreender a particularidade do processo de construção das identidades a partir das mudanças estruturais e institucionais das agências tradicionais da socialização"?

No intuito de encontrar respostas, compreende, preliminarmente, que o habitus, enquanto construto individual, passa a sofrer interferências de diversas vertentes culturais e sociais, o que interfere diretamente no processo identitário. (SETTON, 2002, p. 60). Neste ínterim, a autora conceitua habitus, o vislumbrando como "um instrumento conceptual que me auxilia pensar a relação, a mediação entre os condicionamentos sociais exteriores e a subjetividade dos sujeitos." (SETTON, 2002, p. 61). Refere ainda, que tal conceito se vê engendrado no passado, com alguns reflexos no presente, não apontando, portanto, para o futuro, ainda que esteja em constante modificação. Assim, refere que "Habitus não é destino. Habitus é uma noção que me auxilia a pensar as características de uma identidade social, de 
uma experiência biográfica, um sistema de orientação ora consciente ora inconsciente." (SETTON, 2002, p. 61).

Neste caminhar, segundo o pensar de Bourdieu, repetimos comportamentos sem saber que estamos o fazendo, em razão de que esses comportamentos não são aprendidos conscientemente, mas sim, incorporados por meio de mecanismos inconscientes, quando o corpo é tomado pelas estruturas da sociedade. É claro que, por vezes, podem ser também incorporações conscientes, sendo o habitus, por vezes, paradoxal.

Para o autor supracitado, conforme aduz Setton, o indivíduo não é mero suporte da estrutura. Analisando assim, o caráter identitário aqui proposto, as vivências e segregações de alguns grupos, podem ter estreita ligação com estas práticas aprendidas ao longo da vida, manifestadas pelo habitus, tendo como exemplo, a família, onde aprendemos a distinção, por exemplo, entre homem/mulher, e como cada um deve agir (meninas vestem rosa e meninos azul). Ou, quando não vemos problema em uma mulher de estatura alta casada com um homem de estatura baixa, mas vemos problema em um casal gay, ou em uma mulher Trans (pelo viés identitário diferente, que incomoda), esta é a clara representação da incorporação da estrutura nos indivíduos, que agem com base nos símbolos que adquiriram ao longo da vida.

Mediante tal complexidade de análise social, resta claro que o mundo mudou, sendo necessário, portanto, um novo olhar frente às mudanças, com a adoção de novos paradigmas e a abertura para a pluralidade de sujeitos e grupos, almejando, assim, um viés social e equânime às vivências sociais. Neste sentido, este ensaio propõe uma reflexão acerca de identidade e identidade Trans, sem ignorar os fragmentos oriundos destas tantas mudanças sociais e das múltiplas formas com que estas temáticas se apresentam nos espaços e no imaginário dos indivíduos. Busca-se, portanto, a quebra da resistência em modificar-se, em reconhecer os diferentes (Trans), como parte do todo.

Neste aspecto, é visível que os sujeitos contemporâneos expressam, cada vez mais, uma infinitude de identidades, transitando em diversas redes de relações, o que acaba tecendo uma realidade fragmentada em diversos clãs identitários, os quais se constroem coletivamente, mas ricos em singularidades (SALGUEIRO, 1998, p. 44). Assim, discutir acerca da identidade requer, ainda que de forma superficial, compreender que as relações entre indivíduos e a sociedade perpassam sua construção. Neste sentido, Durkheim defende que "é da sociedade que deriva tudo o que é essencial à nossa vida mental. [...] a ela devemos 
o nosso império sobre as coisas, o que faz parte de nossa grandeza." (DURKHEIM, 2015, p. $83)$.

Em sendo assim, é na e pela sociedade que o processo identitário se manifesta, e, por este viés, corpo e identidade possuem, então, uma relação umbilical, formando uma espécie de tripé com a sociedade, sendo que, neste emaranhado de relações, ambos se constituem. Logo, o coletivo impacta diretamente no individual, na formação de cada identidade como única, mas, ao mesmo tempo, igualmente, coletiva. A identidade, portanto, se constrói, tanto de forma simbólica, quanto social, de acordo com o espaço-tempo (WOODWARD, 2000, p. 9).

Isto é, na ótica de Woodward, pensar que a identidade advém do simbólico, do social, mas, igualmente das vivências do corpo, e dos espaços onde este transita e se manifesta. Neste aspecto que permeia a visibilidade e o julgamento dos corpos, Bauman aduz que:

O corpo não é somente o local e a ferramenta do desejo, mas também um objeto desse desejo. [...] o corpo é o local de nosso self em permanente exposição, e as pessoas tendem a julgar pelo que podem ver. Mesmo que o corpo não passe de um invólucro do que tomamos como nossa "vida interior". (BAUMAN, 2010, p. 166, grifo nosso).

Compactuando com este pensar, Santos e Lucas defendem que a identidade tem total relação com o corpo, pois, na medida em que este é carregado de traços biológicos, igualmente constrói a identidade e sua biografia arraigada em suas vivências (SANTOS; LUCAS, 2015, p. 149).

As vivências do corpo (e por consequência, dos sujeitos), então, seriam uma espécie de fronteira que cotidianamente define e expressa o que cada indivíduo é, sendo o corpo, por consequência, um constante suporte identitário, na medida em que, por meio de descobertas e experiências deste, a identidade passa a ser moldada e, igualmente, desconstruída. (WOODWARD, 2000, p. 15). Por seu turno, Lucas complementa alegando que:

\footnotetext{
A identidade é uma categoria problemática e paradoxal. Nasceu para indicar mais do mesmo, uma correspondência de repetição entre características iguais, e adquiriu com o advento da modernidade uma conotação de identificação e de diferenciação. O certo é que a identidade, como veremos, se constitui na relação com seu oposto, com sua diferença contingente. Vive de ambivalência. Alimenta-se de contradição e negação permanentemente. Inclui excluindo. (LUCAS, 2013, P. 155).
} 
Neste sentido, a historicidade, o corpo, as experiências e as trocas junto à coletividade, dão forma às identidades, as quais estão intimamente ligadas às condições materiais e sociais de cada indivíduo, e passam por rotineiros julgamentos morais. Mas, o que seria então a identidade? De forma genérica, pode se buscar em Hall, a ideia de que a identidade não é fixa e, sim, mutável se movimentando de acordo com as mudanças sociais. Em sendo assim,

[...] à medida que os sistemas de significação e representação cultural se multiplicam, somos confrontados por uma multiplicidade desconcertante e cambiante de identidades possíveis, com cada uma das quais poderíamos nos identificar - ao menos temporariamente. (HALL, 2006, p. 13, grifo nosso).

Por este viés, identidade é aquilo que nos define em dado momento (eis que não é algo fixo), é o conjunto de símbolos, historicidade, sentimentos, características que expressam o sujeito junto à sociedade, todavia, é passível de (re)construção a todo tempo, pois, ao passo que o ser humano evolui, os contextos sociais igualmente se modificam, desconstruindo (ou ao menos buscando) antigos padrões, e abrindo-se para o novo. Assim, o interior identitário conversa com o exterior (sociedade), o que acaba formando encontros e desencontros com a realidade em que cada identidade irá se inserir (SANTOS; LUCAS, 2015, p. 149). Já, na visão de Castro:

A identidade, em sua acepção mais radical, pode funcionar também como ferramenta moral, pois dita o que é possível e o que não é possível, o que é aconselhável e o que não é, para um grupo em determinado contexto histórico e político. Assim, para dar-se como coisa que sente o corpo precisa estar antes de tudo destituído de tais regras que são, na realidade, externas ao seu próprio desejo, somente assim é possível uma vivência da experiência corporal que escape ao plano do sentido, e adentre ao da sensação, ou da presença. (CASTRO, 2015, p. 39).

Acerca das identidades e das discussões e estudos que a permeiam, Hall ainda menciona que,

[...] as velhas identidades, que por tanto tempo estabilizaram o mundo social, estão em declínio, fazendo surgir novas identidades e fragmentando o indivíduo moderno, até aqui visto como um sujeito unificado. A assim chamada "'crise de identidade" é vista como parte de um processo mais amplo de mudança, que está deslocando as estruturas e processos centrais das sociedades modernas e abalando os quadros de referência que davam aos indivíduos uma ancoragem estável no mundo social. (HALL, 2006, p. 7). 
Sob esta perspectiva, poderia se dizer que algumas identidades estariam confrontando com outras historicamente estabelecidas como "padrão" do ponto de vista moral, social, e político-cultural. O ideal de identidade engessada passa, assim, por uma fragmentação dos sujeitos que, diuturnamente se reinventam, desobedecendo toda e qualquer regra de conduta. Ainda neste contexto, Hall defende que:

Esse processo produz o sujeito pós-moderno, conceptualizado como não tendo uma identidade fixa, essencial ou permanente. A identidade torna-se uma "celebração móvel": formada e transformada continuamente em relação às formas pelas quais somos representados ou interpelados nos sistemas culturais que nos rodeiam. (HALL, 2006, p. 13-4).

Neste sentido, partindo de uma análise dos corpos e identidades, importa dizer que a identidade não se define, neste caso, pelo fator biológico e, sim, por meio da história e das vivências de cada sujeito, bem como, pela forma como se reconhece e se autoidentifica. Assim, colaborando com as reflexões acerca das mudanças da sociedade e do conceito de identidade, Bauman preleciona no seguinte sentido,

[...] Podemos dizer que a modernidade se especializou em transformar as coisas zuhanden (à mão) em vorhanden (simplesmente dadas). Ao "colocar o mundo em movimento", ela expôs a fragilidade e a instabilidade das coisas e abriu a possibilidade (e a necessidade) de remodelá-las. (BAUMAN, 2008, p. 128).

A afirmação acima acarreta inúmeras consequências sociais, em razão de que desafia o que há décadas está posto e fixo no sentido identitário. Neste novo contexto cultural e social, múltiplas são as formas identitárias que transitam na coletividade, as quais, por certo, não deveriam necessitar obedecer a padrões identitários impostos socialmente, e sim possuírem o direito à liberdade de expressão, bem como, o direito à diferença.

\section{DIFERENÇA: UM OLHAR IMERSO NA ALTERIDADE}

Como ora sinalizado, ao construir sua identidade, os sujeitos passam a ser identificados no meio em que vivem por intermédio das características desta construção, o que se dá por traços moldados de acordo com suas vivências e trocas sociais e culturais. Por outro lado, a identidade, após tomar corpo, passa a produzir o que se entende por "diferença", 
o que decorre das interações das identidades com grupos, espaços sociais e símbolos culturais, se constituindo, portanto, como uma espécie de paradoxo, tal qual aduz Lucas:

Livra-se, a identidade, do conceito de essência, mas incorpora a dimensão da temporalidade e da historicidade. É elaboração permanente que se alimenta de diferenciações e de ambivalências. Seu paradoxo é a sua própria condição de possibilidade. Existem identidades porque não é possível uma identidade absoluta. Cada uma delas vive da negação de sua diferença. (LUCAS, 2013, p. 160, grifo nosso).

Todavia, a diferença, historicamente, produz discriminações e violações de direitos, na medida em que nem sempre a sociedade reconhece o "diferente" como sujeito, ou como seu semelhante. Nesta perspectiva, Santos e Lucas referem que a problemática da diferença não é atual, e que sempre esteve presente em diversas esferas sociais, ainda que, por algum tempo, as mazelas por ela causadas possam ter sido veladas, diante da dominação ocasionada pela anulação das singularidades de certos grupos e indivíduos, na medida em que pela diferença, foram inferiorizados, a exemplo das minorias étnicas e sexuais. (SANTOS; LUCAS, 2015, p. 30-31).

Desse modo, na tentativa de se compreender brevemente o que seria a diferença, Woodward a conceitua como algo sustentado na exclusão, na ausência de semelhanças entre o sujeito e o outro, ou entre uma identidade e outra. (WOODWARD, 2000, p. 9). Em outras palavras, as identidades divergentes, por serem diferentes do padrão macho/fêmea, tornam-se alvo de preconceito e/ou segregações onde transitam, e, neste sentido, a diferença, pelo viés ora referido, ignora e inferioriza a diversidade existente na sociedade. É nesta ótica que Fernandes aduz que:

Quando se pressupõe que todos têm que ser idênticos uns aos outros, aqueles que não se enquadram na igualdade almejada são situados "fora do mundo" social. A concepção de identidade permeada pela ideia da igualificação consolida a existência dos processos de segregação. A identidade tem relação direta com a alteridade, que significa distinção, o outro que é distinto diferente do mesmo. (FERNANDES, 2006, p. 4).

Portanto, a diferença - que sempre existirá - necessita ser praticada pelo viés da alteridade e não da exclusão, o mesmo devendo se dar no campo do Direito, o qual deve normatizar a sociedade buscando inserir todos os grupos na seara protetiva. Nesse sentido, na ótica de Touraine, 
[...] É na vida cotidiana que se introduz o reconhecimento do outro como sujeito. Ou, ao contrário, a vontade de destruí-lo. É na vida cotidiana que começam a ser elaborados os métodos de produção e as formas de consumo através das quais um modo de subjetivação toma forma. (TOURAINE, 2009, p. 215).

Entende-se, portanto, que é nas trocas coletivas que se pode pensar a alteridade e a equidade para com os diferentes, por esta razão, há que se pensar em equidade e não em igualdade, na medida em que a ideia de que todos devem ser iguais, ignora e impede que a diferença seja vista como positiva para a sociedade. (LANZ, 2017, p. 133). De modo que, para romper com a lógica dominante - de exclusão ao diferente - a alteridade ${ }^{3}$, segundo Warat, seria uma ferramenta importante de inclusão, não se podendo pensar em evolução social, ignorando a diversidade. Desta feita, alteridade seria uma forma de renúncia das velhas formas de olhar o diferente, buscando em suas singularidades, formas igualmente importantes e válidas de expressão identitária.

Tal afirmação se dá, na medida em que a sociedade parece avançar, conforme menciona Bauman, de forma líquida, desconsiderando aspectos fundamentais para se compreender a diferença não de forma negativa, mas, sim, de maneira construtiva. Fernandes, portanto, aduz que:

\begin{abstract}
Se diferenciar no mesmo processo de se identificar deveria ser concebido como uma forma criativa e alternativa de inserção social. Nessas circunstâncias, tratar-se-á de criar formas alternativas de estar no mundo da vida. O que está em questão como fundo desta discussão é a necessidade de inclusão de todas as diversificadas expressões humanas. Não se trata de diferenciar para demarcar divisões de possibilidades e impossibilidades, trata-se de contemplar no mundo social a diversidade da condição humana. (FERNANDES, 2006, p. 8).
\end{abstract}

Com isso, defende-se que a diferença, cada vez mais rutilante nos dias atuais, deveria, via de regra, integrar os sujeitos e grupos, modificando a realidade de fragmentação que ainda se vivencia atualmente. A sociedade historicamente se formou de forma homogênea, onde grupos que se impuseram como "normais", ou seja, como detentores do padrão ideal no sentido cultural e identitário, passaram a hierarquizar as identidades, empurrando para a margem social aquelas identidades que não se assemelhavam ou se identificavam com estas matrizes de tradições identitárias.

\footnotetext{
${ }^{3}$ A alteridade aqui mencionada tem como objetivo enfatizar a importância de colocar-se "ao lado" do outro, do diferente, e não se colocar "em seu lugar" pois esta possibilidade se torna impossível, eis que cada sujeito é único e singular, sendo detentor de sua identidade que, por óbvio, não é "transmissível" a outrem.
} 
Neste sentido, a sociedade se formou sob a divisão identitária, onde a diferença delimita espaços a serem ocupados por determinados sujeitos. Este processo elege, de forma vertical, algumas identidades como parâmetro social, estigmatizando as que se colocam como diferentes. Em suma, a identidade dominante é aquela tida como positiva, negativando, deste modo, as demais, e, neste horizonte, a identidade é engessada no terreno da diferença. (TOMAZ, 2000, p. 83).

Não se pode mais vislumbrar que a sociedade siga fazendo da diferença algo engessado e ensejador de exclusões. Há que se pensar, portanto, na diferença como agregadora e fomentadora da diversidade, do multiculturalismo e da alteridade, buscando a compreensão de que "o outro", ainda que diferente, é parte do todo onde os sujeitos transitam, e, em suas singularidades, deve ser respeitado, incluído, e tratado como sujeito de direitos, sendo, neste terreno da diferença e da luta por ela, que se encontram, também, as mulheres Trans, as quais diuturnamente se veem à margem da sociedade, sem a efetiva inserção e reconhecimento em espaços públicos e privados.

\section{CORPOS TRANS: (TRANS)CENDENDO A DIFERENÇA}

Preliminar à análise dos corpos Trans é fundamental a compreensão de que o corpo aqui abordado não parte da ideia "física", Sarks em grego, ou, ainda, do pressuposto de que os sujeitos o possuem desde o nascimento. Diz-se isso, em razão de que no entorno da ideia de Sarks, de "carne", existe uma representação social, cultural, econômica e política. São os símbolos oriundos deste contexto que o moldam, dando forma a suas futuras expressões na sociedade, indo de desencontro ao que por vasto tempo foi defendido nas abordagens meramente biológicas e deterministas. (LANZ, 2017, p. 147).

Os corpos Trans, por não se enquadrarem nos modelos "disponíveis", hierárquicos e fixos de identidade, remodelaram-se à sua maneira e desejo, transcendendo padrões e valores morais e culturais, resistindo em meio às segregações a que são submetidos. Em sendo assim, passam a desafiar o arcabouço psicossocial e cultural que se engessou na divisão dos sujeitos, em sua maioria, pela perspectiva "genitalizada", ou seja, pelo rótulo genital que recebem no momento do nascimento. (LANZ, 2017, p. 139). 
Por outro viés, pode-se pensar o corpo Trans pelo olhar de Santos e Lucas, na medida em que os autores compreendem que este não está imerso em uma superfície plana e fixa onde as relações ocorrem e, sim, o corpo passa a existir em uma sociedade complexa e dinâmica, povoada de plurais, sendo a identidade operada por uma pluralidade de diversas relações, ao mesmo tempo, formando, portanto, um “corpo móvel”, codificando e descodificado, de acordo com suas necessidades e relações sociais (SANTOS; LUCAS, 2015, p. 150-151).

Nesta ótica compreensiva, ainda que a construção inicial da identidade seja em parte individual este processo torna-se paradoxal, pois, ao mesmo tempo, ela se constrói e se reconstrói no ambiente social, nas trocas e, até mesmo, nas divergências e nos descompassos entre os indivíduos diferentes entre si, na medida em que, pelas redes de relações cotidianas, os sujeitos se moldam e se encontram. Neste sentido, conforme o entendimento Baumaniano:

\begin{abstract}
A "era da identidade" está cheia de som e fúria. A busca pela identidade divide e separa; porém, a precariedade da solitária construção da identidade faz com que os construtores de identidade busquem um bode expiatório para pendurar nele seus medos e ansiedades vividos individualmente e executar os ritos de exorcismo [...]. (BAUMAN, 2008, p. 137).
\end{abstract}

Partindo desta premissa de transcendência identitária, as mulheres Trans passaram a desafiar a sociedade que, por muito tempo, permaneceu engessada em um dispositivo binário $^{4}$, qual seja homem/mulher, tendo como bússola identitária, o caráter meramente biológico, que, indubitavelmente, está ultrapassado para análises atuais. Importa dizer ainda que o segmento Trans busca, ao longo da história, vencer os regimes totalitários que, em seus discursos, utilizam argumentos no sentido de que os corpos Trans subvertem a ordem, o que pode dar a ideia de ameaça ${ }^{5}$ ao padrão vigente de sexualidade e identidade (LANZ, 2017, P. 13).

Em sendo assim, a partir das reflexões realizadas, pode-se afirmar que mulher Trans é aquela que assim se reconhece, como mulher, no sentido mais genuíno do termo. Todavia, importa frisar que o caráter biológico nem sempre é fator determinante no sentido identitário

\footnotetext{
${ }^{4}$ Neste aspecto, o dispositivo binário de gênero nada mais é, do que uma construção social, um conjunto normativo que busca historicamente regular condutas sexuais, identitárias e culturais, elegendo identidades oficiais para se expressar socialmente. (LANZ, 2017).

${ }^{5}$ Corroborando tal afirmação, é fundamental recordar que, até pouquíssimo tempo, pessoas Trans eram vistas como doentes, existindo, inclusive, CID advindo da Organização Mundial da Saúde (OMS) no sentido de tratar as transidentidades como "Transtorno de gênero."
} 
Trans. Ou seja, uma mulher Trans pode, perfeitamente, possuir genitália ${ }^{6}$ masculina, eis que o fato de se autoidentificar como "Trans", está intimamente ligado à sua circunstância e dimensão sociopsicológica, sociopolítica e cultural, a qual estabelece um distanciamento das normas de gênero socialmente impostas como corretas (macho/fêmea), não podendo ser confundido com "identidade de gênero" 7 (LANZ, 2017, p. 427). Nesta perspectiva, ser mulher está intimamente relacionado à forma de viver e expressar-se socialmente, desligandose, muitas vezes, da análise de mantença ou não da genitália ${ }^{8}$ masculina, o que, nos dias atuais, tem reconhecimento legal, por exemplo, quanto ao uso do nome do nome social, o qual não mais se atrela a genitália.

Ademais, a ideia fixa de que a genitália deve ser feminina quando da identidade de gênero como "mulher Trans" a objetifica, indo contra o ideal da diferença como direito. Desta forma, diante de tantas particularidades e diferenças, as mulheres Trans, cotidianamente resistem em uma sociedade ainda retrógrada no que diz respeito às identidades divergentes, lutando contra a imposição de que, para uma identidade ser reconhecida, necessitaria aprovação, ou, ainda, passar pelo crivo do olhar da sociedade. Sobre isso, Touraine menciona que "[...] sempre tememos que o que se chama de interesse da sociedade ignore o direito que cada um tem de ser tratado como sujeito, respeitando o que chamamos de direitos humanos fundamentais. (TOURAINE, 2011, p. 127).”.

Neste compasso, ainda que a sociedade tenha avançado no que diz respeito à diversidade, o mesmo se dando em relação à legislação que, pouco a pouco tem dado passos rumo a garantias de direitos às minorias ${ }^{9}$, culturalmente, ainda existe uma espécie de “castração simbólica", na medida em que os estereótipos, muito presentes nos sujeitos considerados "diferentes" ainda marca fortemente os espaços sociais, estigmatizando e segregando quem assim se reconhece.

Urge a necessidade de uma emancipação dos sujeitos que não desejam viver de acordo com as normas historicamente estabelecidas como corretas, ou, ainda, uma emancipação dos

\footnotetext{
${ }^{6}$ Urge a necessidade de um avanço no sentido da genitália não rotular ou hierarquizar os sujeitos, ignorando, assim, o arsenal de pluralidades que os constroem ao longo da vida.

${ }^{7}$ Gênero, como construto social, é uma grosseira forma de simplificar as infinitas possibilidades de expressão dos corpos e dos seres humanos. (LANZ, 2017).

${ }^{8}$ Neste sentido, a sociedade parece buscar afirmar que as pessoas Trans vivem em conflito com seus corpos, quando, na verdade, o conflito parece muito mais social e moral para com quem assim se reconhece, não procedendo, portanto, com o rótulo que é imposto a estes sujeitos.

${ }^{9}$ Destaca-se a decisão do STF, no sentido de que os crimes de ódio contra LGBT'S sejam punidos na forma do crime de racismo, cuja conduta é inafiançável e imprescritível, sendo que tal decisão ocorreu no dia 13 de junho de 2019. (Carta Capital, 2019. s.p.).
} 
desejos, das identidades, um reconhecimento da diversidade. (SANTOS; LUCAS, 2015, p. 127-128). As mulheres Trans não negam suas diferenças, pelo contrário, reivindicam o reconhecimento destas, bem como a visibilidade e o direito à identidade divergente e sua pluralidade de formas e contextos. Defende-se, portanto, o direito à diferença e ao reconhecimento Trans, os quais estão no cerne dos direitos humanos, atentando para a dignidade da pessoa humana, o que se atrela, umbilicalmente, ao direito a autoidentificação, vislumbrando o direito a identidades concretas. (PIOVESAN, 2015, p. 329).

Nesta perspectiva, o Direito, enquanto normatizador social necessita atuar voltado ao mundo da vida, eis que não se pode mais negar a pluralidade de cores e segmentos sociais, bem como de identidades existentes, as quais fazem jus à proteção legal, tal qual preceitua a Carta Magna e o rol de direitos humanos, textos legais que buscam uma sociedade plural, multicultural e voltada ao respeito a todos, sem exceções.

Em sendo assim, parte-se da premissa de um Direito que compartilhe o entendimento de que nada é estanque e que a sociedade está cotidianamente sujeita a mudanças, o que deságua na necessidade de uma visão epistemológica e complexa no que se refere à capacidade de abarcar tamanha diversidade sexual e identitária. Neste viés, a sociedade e o direito necessitam traçar novos rumos, a fim de se obter resultados diversos dos historicamente conhecidos, devendo estes estar voltados aos direitos humanos e ao reconhecimento no que tange às minorias, oportunizando uma vida digna e permeada pelo direito à cidadania e a liberdade, direitos que ainda parecem intangíveis às mulheres Trans, as quais parecem estar predestinadas a viver no limbo da sociedade.

\section{CONCLUSÃO}

O foco deste artigo, como já descrito na introdução, limita-se à análise identitária, em especial, no que se refere às mulheres Trans, bem como, em alguns aspectos acerca da "diferença" existente na seara identitária, e em como esta pode ser vista pelo viés de pluralidade social.

Nestes moldes, a perspectiva central está em salientar que, diante do avanço social, no que diz respeito à aparição de novos clãs identitários, a pluralidade e o multiculturalismo passam a ser realidades temáticas incontestáveis nos dias atuais. Em sendo assim, 
rememorando as palavras iniciais deste artigo, na medida em que estas novas identidades se formam individual e coletivamente, há que se atentar para a corresponsabilidade social, no sentido de compreender a diferença como ensejadora de crescimento, e não como inferior ou prejudicial a quem nela não se reconhece. Para isso, necessita-se romper com o ideal binário de gênero, o qual foi histórica e culturalmente introjetado como ideal aos indivíduos.

Partindo da ideia de identidade móvel, compreende-se, portanto, que a sociedade ainda não abarca a diversidade identitária existente, na medida em que parte desta ainda rotula quem se autoidentifica divergente das normas binárias impostas para se viver, ou seja, os sujeitos que carregam a diferença em seus corpos, a exemplo das mulheres Trans. Prova do aqui referido, são os índices de violência física e psicológica ocorridos com homens e mulheres Trans no Brasil, como já evidenciado no corpo deste texto.

Neste sentido, em se tratando dos corpos Trans, pelo viés do corpo como aparato sociopolítico no sentido identitário, almeja-se a visibilidade social, a qual pode fomentar a busca por inclusão e respeito identitário. Todavia, esta "visibilidade" torna-se paradoxal, haja vista que a exposição dos corpos Trans significa que, quem assim se reconhece, estará no "alvo" dos olhares e julgamentos alheios, desafiando a identidade que lhe foi imposta ao nascer, no intuito de buscar o reconhecimento da identidade escolhida para transitar nos espaços sociais, o que vai de encontro à hierarquia identitária construída socialmente.

Em sendo assim, ainda que a identidade dos homens e mulheres Trans seja um processo individual no sentido de que seus corpos carregam as marcas deste processo, é na coletividade que o fenômeno da hierarquização se dá, ensejando um sistema por vezes opressor para quem necessita buscar equidade identitária.

Em suma, ao analisar o universo Trans, seja pelas questões identitárias, culturais, ou meramente jurídicas, no intuito de responder o questionamento inicial, qual seja: A sociedade caminha para o respeito aos corpos e identidades Trans, seja pelo viés jurídico, ou meramente social, partindo do pressuposto de que a "diferença" pode (e deve) ser vista como positiva, na medida em que uma identidade não busque dominar outra, mas, sim, para que todas as manifestações identitárias possam conviver com respeito e alteridade?

Ao longo da argumentação, observou-se que o caminho a ser percorrido no sentido de avançar-se socialmente para um ideal de se compreender a diferença como positiva, haverá de se romper com a ideia de que estes sujeitos (mulheres Trans) "habitam no corpo errado", ou, ainda, que suas formas de expressão identitárias não são válidas, partindo, então, para o 
reconhecimento de suas diferenças como parte de suas identidades, como a geografia de seus corpos, pois assim, se caminhará para a garantia de que homens e mulheres Trans possam viver com dignidade, cidadania e, igualmente, com o sentimento de pertencimento a uma sociedade que deveria ser de todos, sem qualquer hierarquia identitária.

Há que se desenraizar de uma luta por esta ou aquela identidade como predominante e única, e perceber, na diferença, uma potencial ferramenta para uma sociedade plural, diversa e democrática, livre de sanções sociopolíticas a quem é diferente do que se compreende como ideal identitário, o que pode se dar, em um primeiro momento, por meio do reconhecimento da alteridade como mola propulsora para compreender os novos contextos identitários, os quais não buscam a dominação sobre identidades binárias e, sim, partem da premissa de que o direito à liberdade de seus corpos seja reconhecido.

Tais reflexões almejam a garantia de uma vida com dignidade e cidadania a quem se autoreconhece como diferente, pois, ao se negar a identidade de um indivíduo, a sociedade o empurra para o limbo, para a exclusão, e estas são práticas que necessitam urgentemente ser ultrapassadas, eis que, não se pode pensar que algumas vidas importam mais que outras.

Importante, ainda, ressaltar, nesta conclusão, a importância do ouvir e do ver altero, ou seja, educar-se para uma visão e uma audição em relação à alteridade. Ouvir o outro enquanto outro é muito importante para se criar uma empatia com o diferente. Da mesma forma, ver o outro enquanto outro, faz emergir a capacidade de ultrapassar - de ir além - a visão da mesmidade e da totalidade, conforme nos ensina Levinás, o filósofo francês da outridade ou da alteridade.

Os corpos Trans, sem dúvida, mostram-se estranhos a um olhar e a um ouvir o mesmo. Talvez seja esta a razão das violências que a sociedade comete com tanta crueldade, ainda na atualidade. Compreender a perspectiva de identidades não fixas, de identidades em construção, móveis, possibilita a emergência de uma consciência cidadã em que não se exclui e, sim, se inclui e se respeita a diferença.

\section{REFERÊNCIAS}

BAUMAN, Zygmunt. A sociedade individualizada: vidas contadas e histórias vividas. Tradução José Gradel. Rio de Janeiro. Zahar, 2008. 
BAUMAN, Zygmunt; MAY, Tim. Aprendendo a pensar com a sociologia. Tradução de Alexandre Werneck. Rio de Janeiro. Editora Zahar, 2010.

CASTRO, Daniele. Corpo à deriva: pensando diferença e identidade sob a perspectiva da cultura da presença. Revista Vozes e Diálogo. Itajaí. v. 14. n. 1., 2015.

CARTA CAPITAL. Disponível em: https://www.cartacapital.com.br/justica/por-8-a-3-stfaprova-a-criminalizacao-da-lgbtfobia/. Acesso em: 24 jun. 2019.

DURKHEIM, Émile. Sociologia e filosofia. Tradução de Evelyn Tesche. São Paulo. EDIPRO, 2015.

FERNANDES, Idilia. O lugar da identidade e das diferenças nas relações sociais. Revista Textos e Contextos. Porto Alegre. V. 5. N. 2, 2006.

HALL, Stuart. A identidade cultural na pós-modernidade. Tradução de Tomaz Tadeu da Silva, Guacira Lopes Louro-11. Ed. - Rio de Janeiro: DP\&A, 2006.

LANZ, Letícia. O corpo da roupa: a pessoa transgênera entre a transgressão e a conformidade com as normas de gênero. Uma introdução aos estudos transgêneros. Curitiba: Movimento Transgente, 2. Ed. 2017.

LEONARDO, Paulo Velho. Identidades em movimento: as mutações dos processos identitários e suas repercussões no exercício da cidadania. Porto Alegre-RS. Editora Fi, 2017. Disponível em: http://www.editorafi.org. Acesso em: 18 jun. de 2019.

LUCAS, Doglas Cesar. O cenário das múltiplas identidades na sociedade contemporânea e os paradoxos de sua proteção jurídica. In: CENCI, Daniel Rubens. BEDIN, Gilmar Antonio. (Org.). Direitos Humanos, Relações Internacionais \& Meio Ambiente. Curitiba-PR. Multideia, 2013.

PIOVESAN, Flávia. Temas de direitos humanos. 8 Ed. São Paulo. Saraiva, 2015.

SALGUEIRO, Tereza Barata. Cidade pós-moderna: espaço fragmentado. Revista Território, Lisboa, n. 4, p. 39-54, 1998.

SANTOS, André L. C.; LUCAS, Doglas Cesar. A (in)diferença no direito. Porto Alegre. Livraria do Advogado, 2015.

SETTON, Maria da Graça Jacintho. A teoria do habitus em Pierre Bourdieu: uma leitura contemporânea. Revista Brasileira de Educação. No 20, 2002. Disponível em: http://www.scielo.br/pdf/rbedu/n20/n20a05. Acesso em: 01 ago 2019.

TOMAZ, Tadeu da Silva (org.). Identidade e Diferença: a perspectiva dos estudos culturais. Petrópolis, Rio de Janeiro: Vozes, 2000.

TOURAINE, Alain. Pensar outroramente o discurso interpretativo dominante. Tradução de Francisco Morás. Petrópolis, RJ. Vozes, 2009. 
WOODWARD, Kathryn. Identidade e diferença: uma introdução teórica e conceitual. In: SILVA, Tomaz Tadeu da. Identidade e diferença: a perspectiva dos estudos culturais. Org. Tomaz Tadeu da Silva, Kathryn Woodward, Stuart Hall. Petrópolis-RJ, Vozes, 2000. 